
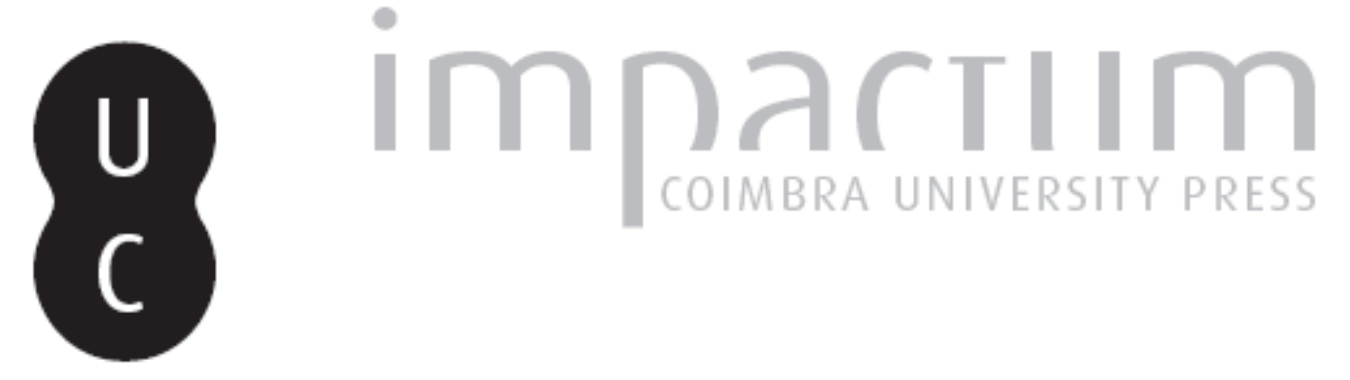
Variações climáticas do passado: chave para o entendimento do presente?: exemplo
referente a Portugal (1675-1715)
Autor(es):
Alcoforado, Maria João
Publicado por: Associação Portuguesa de Riscos, Prevenção e Segurança
URL
persistente:
URI:http://hdl.handle.net/10316.2/40120
DOI:
DOI:https://doi.org/10.14195/1647-7723_6_3
Accessed : $\quad$ 26-Apr-2023 11:06:02

A navegação consulta e descarregamento dos títulos inseridos nas Bibliotecas Digitais UC Digitalis, UC Pombalina e UC Impactum, pressupõem a aceitação plena e sem reservas dos Termos e Condições de Uso destas Bibliotecas Digitais, disponíveis em https://digitalis.uc.pt/pt-pt/termos.

Conforme exposto nos referidos Termos e Condições de Uso, o descarregamento de títulos de acesso restrito requer uma licença válida de autorização devendo o utilizador aceder ao(s) documento(s) a partir de um endereço de IP da instituição detentora da supramencionada licença.

Ao utilizador é apenas permitido o descarregamento para uso pessoal, pelo que o emprego do(s) título(s) descarregado(s) para outro fim, designadamente comercial, carece de autorização do respetivo autor ou editor da obra.

Na medida em que todas as obras da UC Digitalis se encontram protegidas pelo Código do Direito de Autor e Direitos Conexos e demais legislação aplicável, toda a cópia, parcial ou total, deste documento, nos casos em que é legalmente admitida, deverá conter ou fazer-se acompanhar por este aviso.

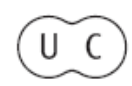




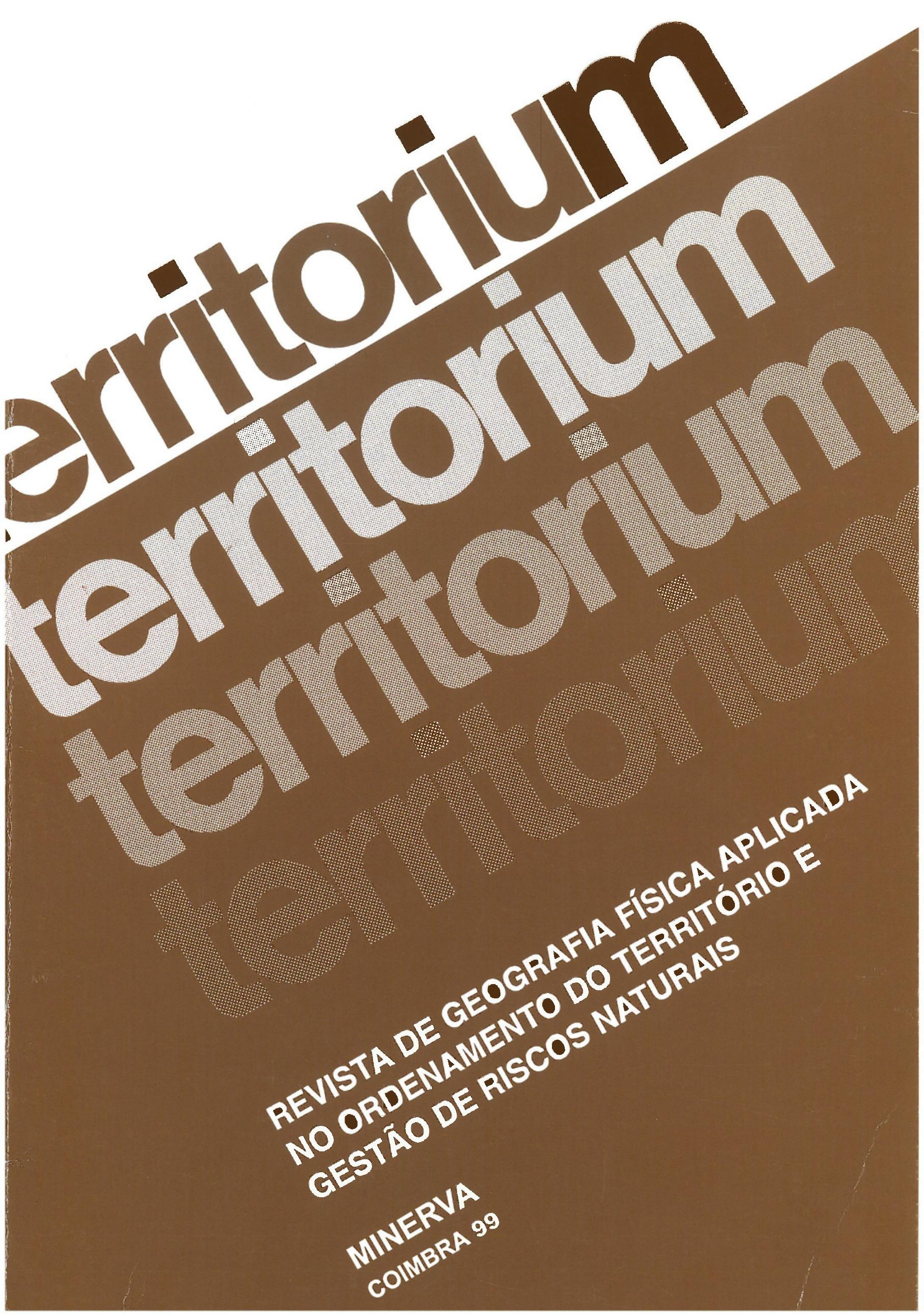




\title{
Variações climáticas do passado: chave para o entendimento do presente? Exemplo referente a Portugal (1675-1715)
}

\author{
Maria João Alcoforado*
}

\begin{abstract}
Resumo:
Refere-se a importância dos estudos dos climas do passado, que resultaram unicamente de causas naturais, enquanto, nos períodos recentes, a acção antrópica pode intensificar ou mascarar as variações naturais. É brevemente apresentado um projecto de climatologia histórica da Europa, sobre o fim do Mínimo de Matnder (1675-1715), período particularmente frio da Pequena ldade do Gelo. Embora não se tenham verificado nítidas tendências, observou-se que os meses de Inverno e de Primavera foram particularmente frios, também ern Portugal. A irregularidade inter-anual da precipitação assemelha-se à da situação presente. Foram detectados meses de severa seca, assim como anos muito chuvosos. São passadas em revista as causas naturais que podem ter contribuído para as variações climáticas observadas no passado.

Palavras chave:

Variações climáticas, climatologia histórica, Pequena Idade do Gelo, Minimo de Maunder, Europa

Résumé:

On souligne l'importance de l'étude des climats anciens, qui n'étaient soumis qu'à des causes naturelles, alors qu'au cours des périodes récentes l'action anthropique peut intensifier ou masquer les variations naturelles. On présente un projet de climatologie historique de l'Europe à la fin du Minimum de Maunder (1675-1715), période particulièrement froide de la Petite Époque Glaciaire. Bien que des tendances très nettes ne soient pas apparues, on peut conclure que les mois de l'hiver et du printemps ont été alors particulièrement froids, même au Portugal. L'irrégularité interannuelle de la température est semblable à l'actuelle. On a reconnu des mois de. sécheresse accentuée et des années très pluvieuses. Les causes naturelles qui peuvent avoir influencé les variations climatiques anciennes sont enfin évoquées.

Mots clés:

Variation climatique, climatologie historique, Petite Époque Glaciaire, Minimum de Maunder, Europe.

\section{Abstract:}

This article is about the importance of studying past climates that result only from natural causes, while, in more recent periods, the changes induced by human activities may heighten or conceal natural changes. A brief fresentation is made of a project on European historical climatology of the Late Maunder Minimum (1675-1715). This was a particularly cold period during the Little Ice Age. Although no distinct trends emerge, it is understood that the winter and spring months were especially cold, including in Portugal as well. The inter-annual precipitation irregularity is similar to that in the present time. Months of severe drought as well as years of heavy rain were detected. We will look into the natural causes that may have contributed towards the climatic changes observed in the past.

Keywords:

Climate variation, historical climatology, Little Ice Age, Maunder Minimum, Europe.
\end{abstract}

\section{Introdução}

As sociedades humanas estão estreitamente adaptadas ao ritmo anual do clima. A arquitectura, o vestuário, os hábitos de lazer ajustam-se ao aproveitamento das potencialidades do clima ou, pelocontrário, à luta contra os factores limitantes. Grande número de tecnologias desenvolvem-se em função das condi-

\footnotetext{
* Centro de Estudos Geográficos. Universidade de Lisboa.
}

ções atmosféricas esperadas, nos diversos locais, e nas várias estações do ano.

A variação estacional dos estados do tempo é familiar aos habitantes de cada região, sentindo-se a população "traída" se o ciclo das estações se altera. Muitos dos desvios duradouros às condições esperadas traduzem-se em desconforto, doença, prejuízos económicos e mesmo perdas de vida humanas. Então começa a inquietação, às vezes mesmo o alarme: estará o clima a mudar? 
No presente estudo, pretende-se chamar a atenção para a utilidade do conhecimento dos climas do passado para o entendimento do presente (e eventualmente a previsão do futuro) no que toca às variações climáticas. Assim descrevem-se os objectivos e principais conclusões de um projecto sobre esta temática, que agora terminou. Será particularmente desenvolvido um exemplo referente a Portugal. ${ }^{(1)}$

\section{Terminologia}

Muitos dos problemas nas discussões sobre as variações climáticas prendem-se com imprecisões da terminologia. Esta é, segundo HARE (1985), arbitrária mas necessária. Definem-se brevemente alguns termos, a partir de um compromisso entre as propostas de HARE (1985) e de BÄRRING (1992). A variabilidade é uma característica intrínseca do clima, assim como o ruído climático; estes dois conceitos não se devem confundir com variação climática. Assim, o ruído é a porção da inconstância climática, atribuída à alternância dos estados do tempo, podendoeventualmente traduzir-se em pequenas diferenças nas médias. A variabilidade climática é medida pelos desvios de valores mensais, estacionais, anuais ou de grupos de anos em relação a valores médios de um período determinado: não é por um Inverno ser muito frio que necessariamente nos estamos a aproximar de uma época glaciária. As flutuações (modificações periódicas ou aleatórias pouco duradouras de um elemento climático em torno de um parâmetro central) exprimem a variabilidade do clima.

Bärring (1992) distingue mudança climática ("climatic change") de variação climática ("climatic variation"), embora os dois termos apareçam como sinónimos em vários dicionários na maior parte das línguas (incluindo em português). A primeira corresponde a diferenças entre médias de períodos longos (numerosas décadas ou séculos), sendo a segunda medida pelas diferenças entre valores médios de um elemento climático entre períodos mais curtos. Tanto as variações como as mudanças climáticas se podem traduzir por descontinuidades (variações bruscas e permanentes) ou por tendências, que indicam evolução num determinado sentido.
(1) Parte da matéria exposta em 4.2 e 6.2 consta das Actas não publicadas do III Simpósio Brasileiro de Climatologia Brasileira, divulgadas em CD-Rom.

\section{Interesse do estudo objectivo dos climas do passado}

Otema das variações climáticas, tratado e discutido actualmente a todos os níveis, continua bastante controverso. Em certos artigos dos orgãos de comunicação social, o homem é considerado como o principal agente das variações do clima. Por exemplo, no artigo do jornal $O$ Público "Mudança climática mata mais"(BOTELHO, 1998) considera-se que o "Homemé, cada vez mais, actor e vítima das mudanças climáticas" e, mais à frente, citando R. Watson, que "as mudanças climáticas se devem à acção humana". Estaria correcto se se tivesse escrito "..se devem também à acção humana". As causas naturais das variaçõese mudanças climáticas são, não raro, desconhecidas do grande público; este às vezes também ignora que, desde o início da história da Terra, ocorreram mudanças climáticas de muito maior amplitude do que as do século $\mathrm{XX}$, algumas estreitamente relacionadas com a deriva dos continentes e as orogenias. É claro que são fenómenos a escalas temporais muito diversas, por vezes difíceis de apreender. O ser humano tem dificuldade em admitir que a duração da sua vida é muito curta, quando comparada com a da Terra e tem uma tendência natural para empolar os acontecimentos presentes, mais pormenorizadamente conhecidos e que o podem afectar directamente.

De entre os inúmeros autores que se têm debruçado sobre a inconstância actual do clima, parece notar-se uma pequena inflexão no papel atribuído às variações naturais. Nas últimas décadas, grupos de cientistas a trabalhar neste assunto, por exemplo o grupo de trabalho do International Panel on Climatic Change - IPCC (HOUGHTON et al, 1990) sub-valorizam as causas naturais da variação climáticas, embora nunca as neguem e as refiram brevemente. Mais recentemente apareceram alguns artigos dedicados quase exclusivamente às causas naturais das variações climáticas como as alterações da radiação solar, também dependente do índice de turbidez da atmosfera devido às erupções vulcânicas explosivas (MANN et al., 1998; BRIFFA et al., 1998; PYLE, 1999). As teorias de Milankovitch sobre as causas astronómicas das variações da climáticas, refutadas entre os anos $50 \mathrm{e}$ meados da década de 70 (JOUSSAUME e GUIOT, 1999), voltaram a ser olhadas com interesse. J.P. PEIXOTO, na sua obra de divulgação sobre as variações climáticas (1987) descreve-as pormenorizadamente. No segundo relatório de síntese do IPCC (HOUGHTON et al., 1996), é já mais desenvolvido o estudo das causas naturais das variações climáticas e é dada ênfase à influência dos aerossóis de origem antrópica, que podem retardar a intensificação do efeito de estufa.

Assim, para tentar antever possíveis alterações do clima, devidas à acção humana, é necessário 
conhecer a variabilidade natural nos últimos séculos, tal como foi referido numa curta nota da revista Nature, com o sugestivo título "O passado como guia para o futuro" (HEGERL, 1998). Com a mesma intenção, foi lançado, em 1996, o projecto $A D V I C E$ (Annual to decadal yariability in climate in Europe) ${ }^{(2)}$. A premissa era a seguinte: se se conseguir entender as causas naturais dos climas do passado, será mais fácil isolar, na actualidade, a parte antrópica das variações climáticas e prever o futuro, em função de vários cenários possíveis de actuação da humanidade. A área de estudo seleccionada foi a Europa (a que se juntou a Islândia e o médio Oriente), devido à riqueza de informação, uma parte já explorada à data do início do projecto (LAMB, 1982; PFISTER, 1994; FRENZEL et al.,1994; GROVE, 1988).

O aquecimento actual iniciou-se a seguir à Pequena Idade do Gelo, em que a temperatura foi inferior em 0,2 a 0,5 $5^{\circ} \mathrm{C}$ ao período 1902-1995 (MANN et al.,1998); teve início no século XIV (HOLZHAUSER et al., 1998, citado por WANNER, 1998) ou no século XVI (GROVE, 1988; PFISTER, 1999) e prolongou-se até meados do século XIX. Não foi um lapso de tempo isento de flutuações climáticas, tendo incluído décadas particularmente frias.

No decurso da Pequena Idade do Gelo, um dos períodos com temperaturas muito baixas (e actividade solar reduzida) ocorreu entre 1645 e 1715 e foi denominado Mínimo de Maunder (nome de um superintendente do observatório de Greenwich). No âmbito do ADVICE, foram escolhidos, para estudo mais aprofundado, os anos entre 1675 e 1715 (Late Maunder Minimum - LMM - na bibliografia em língua inglesa) ${ }^{(3)}$, de que se tratará neste artigo.

O lapso de tempo entre 1780 e 1860 (Early Instrumental Period-EIP) foi igualmente seleccionado, devido à possibilidade de coligir documentação suficiente. As principais conclusões estão sintetizadas em JONES et al. (1999). A investigação sobre este período em Portugal permitiu "alongar" a série de Lisboa e conduziu ao estudo da climatologia aplicada no século XIX (ALCOFORADO et al., 1997; ALCOFORADO et al. (a), no prelo).

(2) Participam neste projecto europeu (ENVA4-CT95-0129), a Grã-Bretanhà (sendo os investigadores do Climatic Research Unit de Norwich os coordenadores do projecto), a Alemanha, a Dinamarca, a Espanha, a Grécia, a Islândia, Portugal, a Suécia e a Suíça. O grupo português era constituído por uma Historiadora da Universidade de Évora. Maria de Fátima Nunes, por Geógrafos das Universidades do Porto (João Carlos Garcia) e de Lisboa (António Lopes, Henrique Andrade e Maria João Alcoforado).

(3) O fim do "Mínimo de Maunder" será, daqui em diante designado pelas iniciais LMM (Late Maunder Minimum).

\section{Fontes para o estudo do clima antes da exis- tência de uma rede organizada de estações meteorológicas}

\subsection{Fontes para a história do clima utilizadas no Projecto ADVICE}

Recordam-se brevemente os tipos de fontes utilizadas para o estudo da história do clima, seguindo a classificação de PFISTER (1995).

A principal distinção faz-se entre fontes directas e indirectas. As primeiras são todas devidas ao Homem e subdividem-se em:

a) Observações instrumentais (dados numéricos de temperatura, pressão, precipitação, etc.)

b) Documentos contendo descrições de acontecimentos meteorológicos extremos, sequências de tipos do tempo, estado do tempo diário (um exemplo muito interessante encontra-se em DAVEAU, 1997).

As fontes indirectas (proxy-data: "dão informações sobre fenómenos governados ou afectados por parâmetros meteorológicos"(PFISTER, 1995, p.119); podem ser naturais ou devidas ao Homem.

De entre as fontes indirectas naturais, distinguemse as geofísicas (isótopos, sedimentos, moreias) e as biológicas (análise dos grãos de pólen, dos anéis de crescimento das árvores, etc.). Uma descrição detalhada destas fontes é feita por BRADLEY e JONES, 1995, pp. 6-14).

De entre as fontes indirectas antrópicas, que se encontram em documentos como actas das catedrais e das câmaras municipais, memórias, diários, cartas, registos de navegação, registos de hospitais distinguem-se:

a) Fontes documentais escritas contendo informações "para-meteorológicas": indicações de nível da água durante cheias, período de solo coberto de neve, congelação de lagos, rios e também do oceano, referências a falta de água.

b) Fontes documentais escritas contendo informações fenológicas ou "para-fenológicas": data deultrapassagem de certos estádios fenológicos (como a data da floração da cerejeira no Japão, registada há numerosos séculos), conteúdo em açucar do vinho, data da vindima ou da inspecção de campos, para pagamento de imposto da dízima, que reflectiam o estado de adiantamento das culturas (PFISTER et al., 1994).

c) Fontes "materiais": pinturas, gravuras, fotografias, mapas, campos abandonados, vestígios arqueológicos.

Anteriormente ao projecto ADVICE, uma primeira reconstrução qualitativa da pressão atmosférica fora empreendida para o Inverno e a Primavera, entre 1675 e 1704 (WANNER et al., 1994). Os autores 
utilizaram dados instrumentrais de Inglaterra ${ }^{(4)}$, índices de temperatura e de precipitação para alguns locais e várias fontes indirectas com informação parameteorológica e fenológica. Os mapas produzidos mostram a reconstrução das situações sinópticas durante o início do LMM (WANNER et al, 1994; WANNER et al, 1995). Estes mapas, desenhados "à mão", foram o ponto de partida do projecto ADVICE, onde se pretendeu re-analisar os campos de pressão, com base em maior quantidade de dados, para um período mais longo e com o auxílio de técnicas estatísticas de tratamento da informação.

A informação de base foi arquivada na Universidade de Berne, completando um ficheiro já muito extenso reunidoporChristian Pfister("Euroclimhist databank", PFISTER, 1988 e PFISTER et al., 1994). Para o ADVICE, não se dispôs de muito mais informação numérica do que WANNER et al. (1994). As fontes instrumentais resumiram-se à temperatura para a Inglaterra Central ${ }^{(5)}$, para Paris e para De Bilt, nos Países Baixos (só no Inverno), assim como à pressão atmosférica em Paris. Pelo contrário, foi possível coligir bastante mais documentação de fontes directas não instrumentais e de fontes indirectas. Os participantes no ADVICE determinaram índices de temperatura e de precipitação a partir de fontes documentais escritas, seguindo a metodologia preconizada por PFISTER et al. (1994) (ver 5.1). Assim dispôs-se de índices de temperatura para a Alemanha Central, Grécia, Hungria, o Sul de Portugale a Suíça e de índices de precipitação para Barcelona, Hungria, Sul de Inglaterra, Múrcia, Sul de Portugal, Sevilha e Suíça. Utilizaram-se ainda o sea-ice severity index para o Inverno, no Báltico Ocidental e dados relativos à congelação do mar junto à Islândia.

\subsection{Fontes utilizadas em Portugal para o LLM}

No caso português, foram consultadas Fontes Institucionais (Eclesiásticas, das Misericórdias, Municipais)e individuais (livros de memórias, gazetas, opúsculos)(ALCOFORADO et al.(b), no prelo).

\section{a) Fontes Institucionais}

\section{- Eclesiásticas}

No séculoXVII, em Portugal, tal como em Espanha, as secas e o excesso de precipitação (seja as grandes chuvadas devastadoras, seja os anos demasiado húmidos) eram considerados castigo de Deus, ao qual era preciso pedir perdão, por meio de diversos actos litúrgicos, tanto individuais como colectivos. Em Espanha, eram vulgares os "rogos" ou as procissões pro-pluvia, organizados pelas autoridades eclesiásticas locais. Estas procissões tinhamo apoio das autoridades civis, nomeadamente das Câmaras Municipais, o que revela o envolvimento e interesse dos poderes (Estado e Igreja) na concretização destas manifestações, e eram sistematicamente anotadas nas Actas do Cabido do Bispado (BARRIENDOS, 1994 e 1997; MARTÍN-VIDE e BARRIENDOS, 1995).

Em Portugal, só se encontraram 2 notícias sobre "rogos" entre 1675 e 1715, embora apareçam com mais frequência nos documentos de meados e finais do século XVIII. As procisões pro-pluvia mais noticiadas decorreram durante a grande seca de 1694 . Pelo contrário, encontrou-se bastante informação sobre chuvadas e cheias, que impediam o evoluir dos acontecimentos litúrgicos regulares (como as procissões habituais). As fontes eclesiásticas forneceram, assim, fundamentalmente, indicações sobre períodos de precipitação excessiva, interessantes sobretudo quando duravam vários dias, ou mesmo semanas.

\section{- Misericórdias}

Nos Livros de Actas e Lembranças, em que se descreviam as actividades das diversas confrarias, eram, por vezes, incluídas informações datadas sobre o tempo. ${ }^{(6)}$

\section{- Municipais}

Em Fontes Municipais, encontra-se igualmente referência ao "tempo atmosférico". Os paroxismos climáticos deram Iugar a um certo número de medidas tendentes a minorar as respectivas consequências. Foram utilizados os relatos sobre as decisões económicas e sociais tomadas, quando as suas causas climáticas eram explicitamente descritas ${ }^{(7)}$. As principais medidas tinham a ver com a proibição de exportação de carne e trigo, e com limitações no uso da água. A partir de 1705, em que a falta de géneros era devida sobretudo ao seu envio para a frente de batalha (Guerra pela Sucessão, em Espanha, em que Portugal tomou parte), esta fonte foi posta de lado.

(4) À excepção de uma série meteorológica que se iniciou, em Paris, em 1665 (PFISTER e BAREISS, 1994) e de uma outra referente ao Centro de Inglaterra (MANLEY, 1974), as principais séries tiveram início nos séculos XVIII e XIX (a maior parte). BRADLEY e JONES (1995. p.248) referem 18 séries iniciadas no século XVIII, todas elas no Hemisfério Norte.

(5) As referências bibliográficas correspondentes a todos estes índices, encontram-se em LUTERBACHER et al., (1999).

(6) A informação proveniente destas fontes foi recolhida por J.P. Taborda.

(7) A recolha dos dados provenientes das fontes municipais foi feita sob a supervisão de Maria de Fátima Nunes, Professora de Históris na Universidade de Évora e participante do projecto ADVICE. A interpretação dos dados foi um trabalho conjunto da referida Investigadora e da autora do presente texto. 


\section{b) Fontes individuais}

\section{- Memórias}

As Memórias consultadas revelaram-se, na sua esmagadora maioria, inúteis para a investigação em curso. O género memorialístico do século XVII em Portugal é restricto e pouco útil para a investigação sobre acontecimentos profanos (PALMA-FERREIRA, 1981). Paradoxalmente, foi um volume individual de Memórias, que permitiu a reconstrução do estado do tempo em determinados períodos entre $1680 \mathrm{e}$ 1716. O volume das "Memórias Históricas de Lisboa", escritas por Manuel de Almeida, entre 7 de Novembro de 1696 e 2 de Abril de 1716, e editadas por ANTÓNIO PINA CABRAL (1948) constitui a base mais completa de que se dispôs. ${ }^{(8)}$ Infelizmente, Manuel de Almeida não foi até agora identificado: nome comum, escrita vulgar. Sabe-se apenas que morava na Bica de Duarte Belo, em Lisboa, e que era leigo. Embora as notícias não meteorológicas forneçam o fio condutor à narrativa, organizada cronologicamente, existem descrições pormenorizadas de certos acontecimentos meteorológicos e do que Manuel de Almeida entendia serem as respectivas consequências. A ausência de informação pode (ou não) significar a ausência de acontecimentos extremos.

São salientados, neste texto, os dias em que se registam ocorrências que o autor considera dignos de registo: datas importantes para a família real (nascimento dos infantes, baptizados, casamentos, funerais, deslocações), partidas ou chegadas das frotas, batalhas, autos de fé, incêndios, homicídios e festas religiosas. Os únicos factos climático-hidrológicos que, por si só, merecem menção são as cheias (a maioria urbanas). A carestia dos géneros alimentícios é esporadicamente objecto de atenção de Manuel de Almeida, que a associa às agruras do tempo. Toda a informação contida nestas Memórias é de tipo qualitativo e, forçosamente, subjectivo. A intensidade de certos episódios (sobretudo fortes chuvadas) pode ser avaliada através das suas consequências, por vezes descritas pormenorizadamente.

A resolução temporal das notícias varia bastante. Os dados referentes a dias singulares, não deixando de ser interessantes, não foram usados. Algumas destas referências pontuais revestem-se, no entanto, de enorme interesse. Um exemplo é a queda de neve em Lisboa. Nos 37 anos a que diz respeito esta crónica, houve 9 ocasiões em que nevou em Lisboa, o que mostra diferenças seguras em relação à actualidade, e indica que a "sensação" de frio expressa pelo autor, nestas e noutras ocasiões, poderá ter como causa temperaturas mais baixas que as actuais (nos últimos 40 anos, só nevou em Lisboa em Fevereiro 1954).

(8) Agradece-se à Professora Doutora Suzanne Daveau a indicação desta fonte, que se viria a revelar imprescindível.
A informação está muito desigualmente distribuída ao longo do ano, sendo muito mais frequente para os meses de Inverno, particularmente Janeiro. Comparativamente, existe muito menos informação para o Verão. Dos 37 anos, apenas há informação para 8 Verões: 6 terão sido quentes, um fresco e um normal. Seria o autor mais sensível ao frio do que ao calor?É possível, uma vez que se queixa frequentemente de frieiras. Ou, pelo contrário, não terá havido outros Verões excessivamente quentes? Éigualmente possível, uma vez que assim acontecia em grande parte da Europa, nomeadamente em Espanha (BARRIENDOS, 1994; PFISTER, 1992; LUTERBACHER et al., 1999)

\section{- Gazetas e Opúsculos ${ }^{(9)}$}

Certos indivíduos cultos daépoca deixaram escritos, que contêm as suas preocupações relativamente a fenómenos sociais, culturais e meteorológicos. As obras que se revelaram mais úteis foram a Gazeta composta em forma de carta de José S. da Silva (Académico de História), referente ao período 1701-1716 e de periodicidade quinzenal (SILVA, 1931); assim comoos Opúsculos chronologicos de J.B.Castro e os Apontamentos para a Província do Alentejo de F. de Oliveira (Manuscritos citados em ALCOFORADO et al. (b), no prelo).

\section{Métodos e Técnicas}

\subsection{Os índices de temperatura e precipitação}

Como se dispunha de um muito pequeno número de dados quantitativos (ver 4.1), foi necessário transformar a informação qualititativa em valores numéricos. Com esse fim seguiu-se a metodologia de PFISTER (1992 e 1994) e de PFISTER et al., (1994).

A cada mês foi atribuído um valor numérico entre $-\mathbf{3}$ e $+\mathbf{3}$, no caso de se dispor de informação facilmente quantificável como, por exemplo, a data da floração dacerejeira em anos sucessivos. O valor $+\mathbf{3}$ corresponde a um excesso máximo e o valor $\mathbf{- 3}$ ao maior deficit. O valor 0 corresponde aos meses "normais" (e, também, àqueles para os quais não existe informação suficiente $)^{(10)}$. No caso da informação ser unicamente qualitativa, como no caso português, os índices mensais variam entre -1 (meses "secos" ou "frios") e +1 (meses "chuvosos" ou "quentes" para a época do ano). $\mathrm{O}$ valor $\mathbf{0}$ corresponde, tal como atrás foi descrito, aos meses "normais". Os índices anuais e estacionais são obtidos pela soma algébrica dos

(9) A informação proveniente destas fontes foi recolhida por J.P. Taborda

(10) Note-se que of facto de não existir informação quer muitas vezes dizer que o mês foi "normal", uma vez que os autores não sentiam necessidade de escrever sobre o tempo. No entanto, não se pode concluir que todos os meses para os quais não se dispõe de informação são "normais". 
índices mensais. As "estações do ano" correspondem a períodos seguidos de 3 meses, iniciando-se o Inverno de um de terminado ano em Dezembro do ano anterior. Assim, os índices anuais variam entre 0 e \pm 12 (por exemplo, um índice de temperatura correspondente a -12 significa que todos os meses foram frios) e os estacionais entre 0 e \pm 3 .

Nocaso de Portugal, os índices foram determinados independentemente para Lisboa e para Évora. Baseados em estudos de variação climática recente, em que se verificou semelhança de comportamento temporal das estações de Lisboa e de Évora (MAHERAS et al., 1995), foi preparada uma base de dados conjunta referente ao Sul de Portugal

\subsection{O tratamento da informação}

A reconstrução dos campos de pressão foi feita para o Atlântico Oriental e Europa, entre $25^{\circ} \mathrm{W}$ e $30^{\circ} \mathrm{E}$ e entre $35^{\circ} \mathrm{N}$ e $70^{\circ} \mathrm{N}$. As reconstruções foram baseadas numa análise canónica das correlações, em que os dados (directos ou indirectos) das estações actuaram como variáveis independentes e a pressão atmosférica nos diversos pontos de uma grelha como variáveis dependentes (LUTERBACHER et al., 1999).

Os dados dos últimos 90 anos foram usados neste modelo: os primeiros 60 anos (1901-60) para calibrar o modelo e os últimos 30 anos (1961-90) para validar os padrões espaciais reconstruídos de pressão atmosférica, reduzida ao nível do mar.

O modelo de análise canónica de correlação foi seguidamente utilizado para determinar a pressão atmosférica média mensal no LMM. As isóbaras foram desenhadas automaticamente, obtendo-se mapas de pressão média mensal. Estes mapas foram, em várias fases, revistos e comentados pelos diversos membros da equipe. Além disso, foram testados por comparação entre os períodos de calibração e de verificação.

\section{Resultados}

\subsection{Resultados globais para a Europa e Atlântico Oriental}

Para o LMM, a variância explicada pelo modelo é máxima no Inverno (70\%), diminuindo para 56\% tanto no Outono como na Primavera, e para $45 \%$ no Verão. Os padrões sinópticos previstos para o período 1961-90 concordam com os campos de pressão observados no mesmo período, embora os gradientes de pressão não estejam completamente correctos em todas as áreas.

LUTERBACHER, num relatório de difusão ainda restrita (1997), construiu mapas muito interessantes que representam a diferença entre os valores mensais previstos para o LMM e os previstos para 1961-90. No Inverno ocorrem fortes anomalias positivas sobre aEscandinávia e Rússia Ocidental: +6hPaem Dezembro, +4 hPa em Janeiro, +3hPa em Fevereiro. Pelo contrário, observam-se anomalias negativas na Europa Central e Mediterrâneo. Assim, houve, durante os Invernos do LMM mais situações anticiclónicas de bloqueio sobre a Europa, que significam uma mais frequente advecção de ar frio e seco para a Europa Central e Meridional do que no período 1961-90. No Verão, verificaram-se anomalias negativas sobre as Ilhas Britânicas (até - $3 \mathrm{hPa}$ em Julho e Agosto): ocorreram então fortes westerlies, e condições de maior frescura e humidade sobre a Europa Ocidental e Central.

No Outono e na Primavera (ainda segundo LUTERBACHER, 1997), a pressão apresentou-se, no LMM, particularmente alta sobre a Islândia $(+4 \mathrm{hPa}$ em Março e Outubro): indicação de uma depressão da Islândia pouco marcada, enquanto se encontram anomalias negativas nas Ilhas Britânicas e partes da Europa Ocidental (Primavera) e na Europa Ocidental, Central e Oriental (no Outono). Oautor sugere que as depressões de Oeste teriam, nestas estações do ano, uma trajectória mais meridional do que presentemente.

Uma classificação das situações sinópticas do LMM, comparativamente à do período 1961-90, mostra algumas diferenças, nomeadamente uma maior frequência de situações de anticiclone Europeu (ou Atlântico prolongado para Oriente); estes originam fluxo de Leste e NE, que atinge numerosas áreas da Europa meridional. No LMM, a influência marítima invernal (LUTERBACHER et al., 1999) era mais fraca do que actualmente. É igualmente evidenciado que o índice NAO (North Atlantic Oscillation) é incapaz de descrever certas condições específicas do clima na Europa, como as que acabaram de ser descritas (WANNER, 1995 e 1999).

\subsection{Resultados referentes a Portugal}

Para o LMM, em Portugal, há informação térmica apenas para $20 \%$ dos meses, sendo mais abundante a informação relativa às características hídricas (33\%).

Tanto para a temperatura como para a precipitação, foi feita uma comparação dos resultados obtidos para o LMM, com o período 1961-90, para o qual se efectuou uma transformação dos valores numéricos. Atribuiu-se o valor $\mathbf{0}$ aos meses com temperatura ou precipitação compreendida entre o valor da média menos 1 desvio-padrão e a média mais 1 desvio padrão; $\mathbf{- 1}$ foi utilizado para indexar os meses com valores inferiores à média menos 1 desvio-padrão $\mathrm{e}$ +1 , para os valores correspondentes a valores superiores à média mais 1 desvio-padrão. 


\section{a) Temperatura}

Dos $20 \%$ dos meses para os quais se dispõe de informação, $14,5 \%$ são meses frios (sobretudo de Inverno), e 5,5 são meses "quentes" para a estação do ano em que ocorrem.

Quadro I - Frequência (\%) de ocorrência de "índices de
tcmperatura" para o Sul de Portugal, no LMM (1675-1715, ver 5.1) e entre 1961-90 (ver 6.2).

\begin{tabular}{|c|c|c|c|}
\hline & -1 & 0 & +1 \\
\hline Inverno & 28 & 67 & 5 \\
\hline Primavera & 19 & 79 & 2 \\
\hline Verão & 2 & 86 & 12 \\
\hline Outono & 7 & 92 & 2 \\
\hline Ano & 14 & 81 & 5 \\
\hline
\end{tabular}

A) LMM

\begin{tabular}{|c|c|c|c|}
\hline & -1 & 0 & +1 \\
\hline Inverno & 7 & 53 & 40 \\
\hline Primavera & 21 & 52 & 27 \\
\hline Verão & 17 & 63 & 20 \\
\hline Outono & 16 & 43 & 41 \\
\hline Ano & 15 & 53 & 32 \\
\hline
\end{tabular}

B) $196 i-90$

Nos valores anuais, nota-se uma discrepância grande entre a percentagem de meses "normais": $53 \%$ em $1961-90$ e $81 \%$ no LMM, o que significa certamente insuficiência de dados para o LMM (veja-se a nota 10).

As observações mais frequentes e mais fiáveis sobre a temperatura dizem respeito ao Inverno. As frequências dos valores "normais" estão mais próximas (67\% no LMM e $53 \%$ no período entre
1961 e 1990, Quadro I). A proporção de Invernos frios é maior em $21 \%$ no LMM e a de Invernos "quentes" $35 \%$ menor (comparem-se os valores nos Quadro IA e IB). Há portanto concordância com a situação de maior frio Invernal na Europa Central, descrita por LUTERBACHER et al. (1999).

$\mathrm{Na}$ Primavera, os meses "normais" ocorrem em 52\% dos casos em 1961-90, e em 79\% no LMM, o que poderá indicar alguma falta de informação para o período mais antigo. Mas, apesar disso, é interessante comparar as frequências de ocorrências de meses "quentes" e "frios": só em $2 \%$ dos casos há indicação de meses "quentes" para o LMM (+1, Quadro IA) enquanto, no período recente, a percentagem atingiu $27 \%$, expressão numérica das numerosas vagas de calor primaveris das últimas décadas; nos meses "frios", a diferença é pequena (19\% para o LMM e $21 \%$ para 1961-90).

Pelo contrário, a frescura dos Verões, observada noutros locais da Europa, não foi detectada. De qualquer maneira não se pode tirar qualquer conclusão definitiva para Portugal, no Verão e no Outono, uma vez que a informação disponível é claramente insuficiente (vejam-se as percentagens de valores "normais", no Quadro I).

A evolução dos índices de temperatura no Inverno e na Primavera estão expressos na figura 1 . Não se nota qualquer "tendência" clara. Observa-se que os Invernos "quentes" são raros: 1699 e 1707 (invernos tépidos e chuvosos à excepção de Fevereiro 1699); quanto à Primavera, só a de 1705 foi considerada "quente" (unicamente o mês de Junho).

Para muitos Invernos e Primaveras, há indicação de "frio" (fig. 1), embora nem sempre no mesmo ano (Invernos de 1681, 1688, 1693, 1694, 1700 e a partir de 1708; Primaveras de 1684, 1694, 1698, 1699. $1700,1707,1711$ e 1713). Note-se, por exemplo, que o valor -3 (em 1713, na fig.1) significa que houve notícia de frio para todos os meses da Primavera O período frio mais longo foi em 1694 (índices de -2 no Inverno e na Primavera).
Figura I - Variação do Índice de Temperatura no Inverno e na Primavera no Sul de Portugal.

A partir do início do século XVIII, a temperatura começou a aumentar na Europa Central (PFISTER e BAREISS, 1994; PFISTER, 1992, BRÁZDIL et al., 1994), à excepção do ano de 1709 , em que o mês de Janeiro também foi extremamente frio no Sul da Europa (ALCOFORADO et al.(b), no prelo),. Em Portugal o aumento não foi detectado nas fontes consultadas; pelo contrário, os últimos anos do LMM terão sido os mais frios, nomeadamente a partir de 1708, no Inverno e de 1710 , na Primavera.

Nota-se, na figura 2a, o referido aumento dos meses "frios" no último quinquénio (1710-14). Só entre 1690 e 1695 (n5, na fig. 2a), o número de meses "frios" foi maior na Primavera do que no Inverno. Tal facto coincidiu com as duas "secas" de Primavera, em 1698 e 1699.
Fig. 2a - Meses Frios

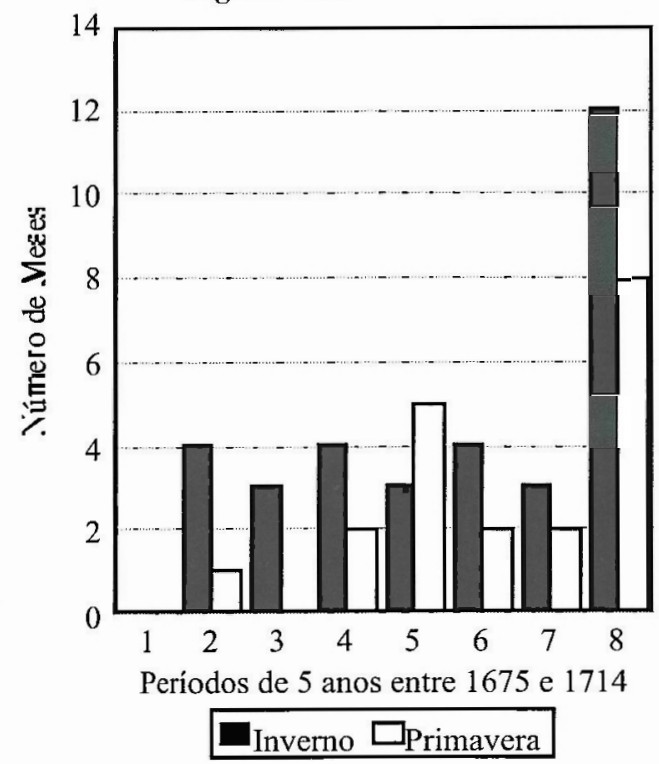

Fig. 2c - Meses Muito Chuvosos

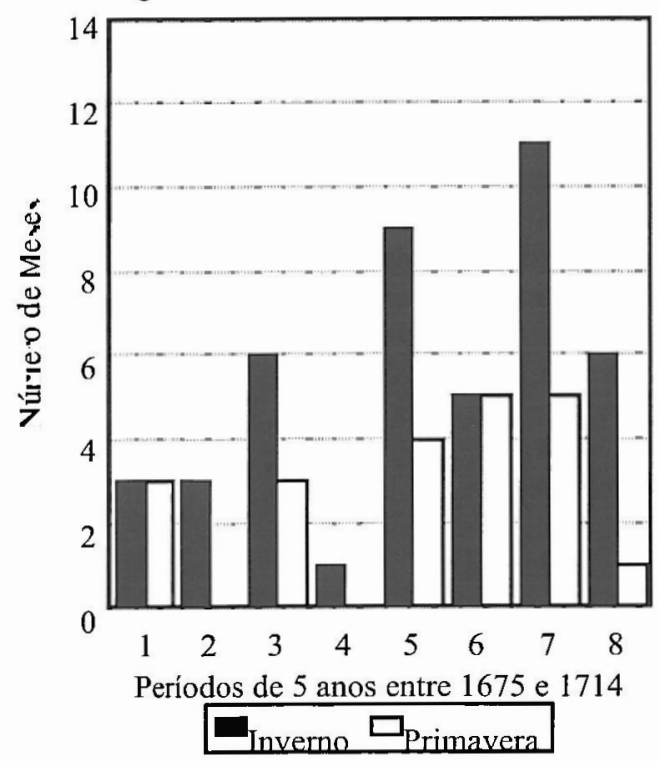

Fig. 2b - Meses Quentes



Fig. 2d - Meses Secos



Figura 2 - Número de meses frios (2a), "quentes (2b), chuvosos (2c) e secos (2d) em períodos seguidos de cinco anos, entre 1675 e 1714 , no Sul de Portugal. 1: 1675-1679; 2: 1680-84; 3: 1685-1689; 4: 1690-94; 5: 1695-99; 6: 1700-04; 7: 1705-09; 8: 1710-1714. 


\section{b) Precipitação}

Quanto à precipitação, existe informação para $33 \%$ dos meses. Nota-se, no Quadro II, que as percentagens de meses ditos "normais" (inflacionadas sempre que faltam dados no LMM) são menores do que no caso da temperatura.

Quadro Il - Frequência (\%) de ocorrência de "índices de precipitação" no LMM (1675-1715, ver 5.1) e entre 1961-90 (ver6.2).

\begin{tabular}{|c|c|c|c|}
\hline & -1 & 0 & +1 \\
\hline Inverno & 18 & 48 & 34 \\
\hline Primavera & 23 & 59 & 18 \\
\hline Verão & 5 & 89 & 6 \\
\hline Outono & 16 & 74 & 10 \\
\hline Ano & 15 & 68 & 17 \\
\hline
\end{tabular}

A) LMM

\begin{tabular}{|c|c|c|c|}
\hline & -1 & 0 & +1 \\
\hline Inverno & 30 & 47 & 23 \\
\hline Primavera & 16 & 49 & 35 \\
\hline Verão & 14 & 78 & 8 \\
\hline Outono & 19 & 51 & 30 \\
\hline Ano & 20 & 56 & 24 \\
\hline
\end{tabular}

B) $1961-90$

As diferenças anuais não são significativas (Quadro II). Verifica-se que, no conjunto, os Invernos são mais chuvosos no LMM e as Primaveras mais secas, do que em 1961-90; ou seja, embora seja possível que as depressões de Oeste tenham tido, nas Primaveras do LMM, uma trajectória mais meridional, tal como sugere LUTERBACHER et al. (1999, ver 6.1), elas não parecem, no entanto, atingir o Sul de Portugal. Em situação zonal, Portugal estaria então influenciado pelo Anticiclone subtropical, imediatamente a sul do fluxo rápido de Oeste. Este facto e a grande frequência de situações anticiclónicas de bloqueio no LMM (Id . e DAVIES, 1998) contribuem para a explicação das numerosas secas portuguesas.

Verifica-se uma forte irregularidade inter-anual dos índices da precipitação no LMM (fig.3). A maior seca ocorreu em 1693/94; há numerosas notícias de gravíssima seca no Outono, no Invernoe na Primavera desse ano. Manuel de Almeida refere que não choveu entre Dezembro 1693 e o dia de S. João (24 de Junho de 1694); a chuvada muito intensa desse dia "por intempestiva fez ainda mais perda que proveito" (CABRAL, 1948, p.32). Nesse ano, há notícias, provenientes de diversas fontes, de rogos em vários pontos do País, a partir do mês de Abril. Como se referiu atrás, 1693/94 foi igualmente um Inverno muito frio. Além deste, citem-se os anos secos de 1700, 1706, 1711, 1714 e 1715. Como anos húmidos, refiram-se $1677,1686,1695,1701$ e 1708. Em qualquer estação do ano, é notória a variabilidade inter-anual (ALCOFORADO et al. (b), no prelo).

Nos gráficos da figura $2 \mathrm{c}$ e $2 \mathrm{~d}$, observa-se que ocorreram mais meses "chuvosos" no Inverno do que na Primavera, particularmente entre 1695-1699 (n 5 na figura) e 1705-1709 $\left(\mathrm{n}^{\circ} 7\right)$. O quinquénio mais seco foi, de longe, o de 1690-1694 ( $\left.\mathrm{n}^{\circ} 4\right)$, tendo o seguinte sido muito mais seco na Primavera do que no Inverno (fig. $2 \mathrm{~d}$ ).

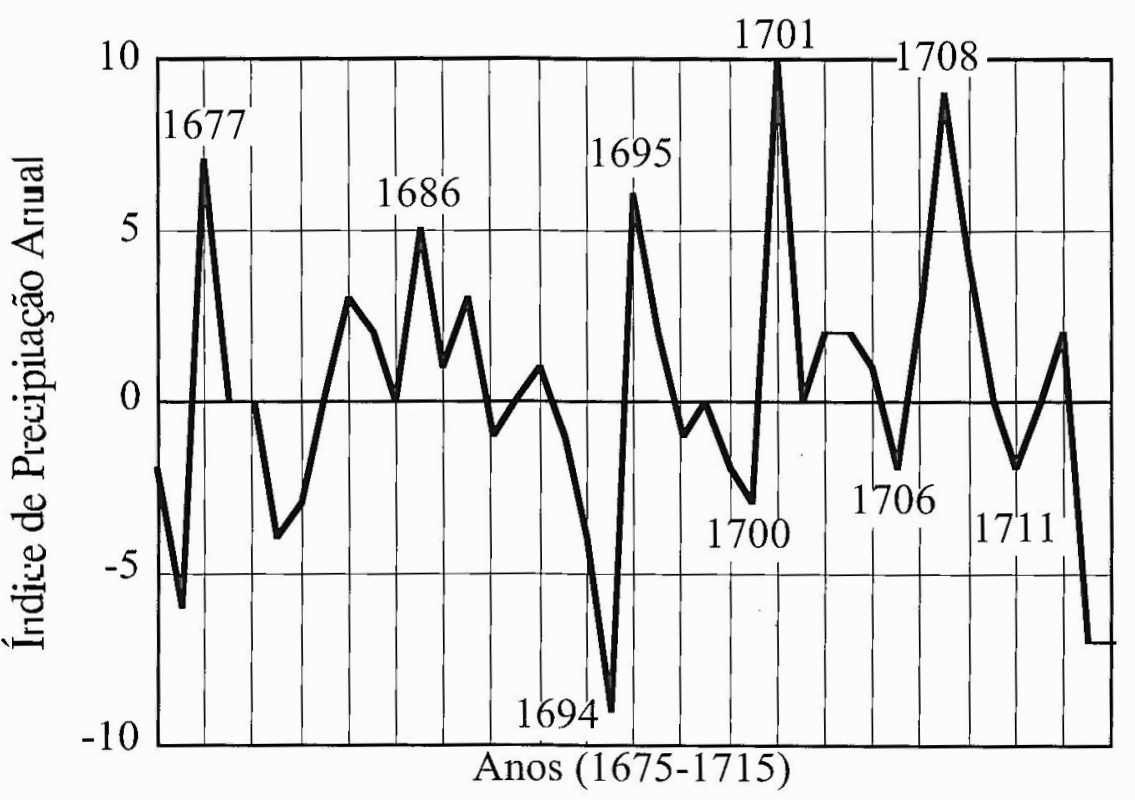




\section{Causas das variações climáticas no LMM}

Há três factores naturais que se sabe terem influenciado as flutuações ou variações climáticas verificadas na Pequena Idade do Gelo e, mais precisamente, no LMM: modificações da radiação solar, erupções vulcânicas e oscilações internas no sistema climático (EDDY, 1976; MANN et al., 1998)

LEAN (1996) encontrou, entre 1610 e 1800 , uma correlaçãode 0,86 entre a reconstrução da temperatura no hemisfério norte e a da radiação solar, indicando uma redução de $0.24 \%$ da radiação solar no LMM. MANN et al. (1998) concluem igualmente haver uma correlação significativa entre a radiação solar que atinge a terra e a temperatura do ar à superfície.

MANN et al. (1998) também examinaram outros "agentes forçadores" (forcing factors) no período 1610-1998, incluindo o índice de turbidez daatmosfera, originado por vulcanismo explosivo. Segundo este autor e BRIFFA et al. (1998), teria havido uma concentração de erupções nas décadas 1660,1670 e 1690 , que teriam contribuído para o arrefecimento estival do Hemisfério Norte.

A resposta do sistema climático a esta (e outras) modificações naturais (ou não) do clima é manifestada por processos complexos no Oceano e na Atmosfera. As trocas globais de massa e de energia, assim como a circulação nos oceanos (dependente também da temperatura da água do mar e da salinidade) e na atmosfera condicionam a circulação regional, neste caso no Atlântico e na Europa (WANNER, 1995 e 1997). O clima de certo local é assim regulado por uma intrincada teia de retroacções, ainda muito incompletamente entendida.

\section{Conclusão}

As condições térmicas e pluviométricas observadas em Portugal provam que, no SW da Europa, as situações sinópticas terão sido, durante o LMM, semelhantes às actuais, apenas com uma maior frequência de ocorrência de situações anticlónicas no Inverno e Primavera, às quais estava associada advecção de ar continental (chegando de NE ou de E), tal como foi observado por LUTERBACHER et al. (1999). A advecção de ar frio de NE é explicitamente indicada pelo autor das Memórias atrás referidas. A advecção de ar frio e seco era normalmente acompanhada de subsidência na média troposfera, o que atenuava ainda os mecanismos conducentes à precipitação e aumentava a secura atmosférica. Por isso se explica que, a este período frio, não tenha correspondido um avanço dos glaciares nos Alpes (WANNER et al., 1995). A maior "continentalidade" do clima da Europa Central e Oriental não é expressa pelo índice NAO
(North Atlantic Oscillation (DAVIES, 1998, WANNER et al., 1995).

Além das baixas temperaturas, notou-se, neste período, uma grande variabilidade interanual das precipitações e a ocorrência de Verões particularmente frescos e chuvosos, na Europa Ocidental e Central, devido ao reforço do fluxo de Oeste, já referido em 5.2. Estas condições não parecem ter-se feito sentir até à latitude do Sul de Portugal. Sendo raros os verões chuvosos, deveriam ter sido alvo de referência pelos autores das fontes consultadas. Estar-se-ia em circulação zonal, com o Anticiclone subtropical influenciando Portugal e, mais a Norte, situações perturbadas de Oeste.

No decurso deste estudo foram uniformizados critérios de análise crítica das fontes e da "quantificação" das informações disponíveis. Só assim o conjunto dos "padrões sinópticos médios mensais", um dos resultados mais importantes do Projecto, pode ser considerado válido.

Foi verificada a existência de flutuaçõesclimáticas, independentes da acção antrópica. Foram esclarecidas as principais diferenças ocorridas, em termos de dinâmica atmosférica, entre o LMM e 1961-90. A pesquisa científica prossegue em várias frentes, citando-se algumas, a título de exemplo:

a) Investigação da diversidade espaço-temporal das variações climáticas recentes, mascaradas pelos valores "globais" ou "hemisféricos". Esta imprescindível tarefa foi empreendida por diversos autores em HOUGHTON et al., (1996), onde são apresentados planisférios de valores observados e previstos por diversos modelos. Num estudo na escala regional, SCHÖNWIESE e RAPP (1997) apresentaram um muito interessante atlas da Europa, com as particularidades espaciais das alterações de temperatura, pressão, precipitação e humidade, no decurso do último século (recensão em ALCOFORADO, no prelo).

b) Desenvolvimento das previsões estacionais do climaEuropeu e da sua relação com a NAO (WANNER, 1999).

c)Aprofundamento do estudo das relações de interdependência entre a atmosfera e os outros subsistemas do sistema climático, nomeadamente a Hidrosfera (WANNER, 1997 e 1999; JOUSSAUME e GUIOT, 1999; HEGERL, 1999), a Biosfera (JOUSSAUME e GUIOT, 1999), a Litosfera e a Criosfera (HOUGHTON et al., 1996). Os resultados permitirão aperfeiçoar os modelos de previsão que, não raro, apenas incluem a atmosfera, ignorando, por dificuldade de quantificação, as retro-acções no sistema climático.

d) Continuação da pesquisa sobre outros períodos como o "Óptimo Térmico Medieval" (HUGHES e DIAZ, 1994). Quanto mais se recua no passado, mais 
difícil é encontrar fontes adequadas e interpretá-las; mas este período terá porventura ainda mais interesse do que o LMM, porque se tratou de uma época "quente" (embora também com flutuações climáticas), sem qualquer influência do Homem. PFISTER (1999) refere a existência de figueiras na região de Colónia (Alemanha) por volta de 1200 e de morangos maduros no Natal, em Liège (Bélgica), em 11 16. Que causas terão provocado estas condições térmicas?

Uma vez entendida a variação natural do clima e isolado o efeito antrópico, será possível determinar com exactidão as medidas prioritárias para minorar as consequências indesejáveis da acção do Homem; talvez então os cientistas disponham de argumentos suficientemente convincentes para que os "decisores" ouçam as suas advertências e sigam os seus conselhos.

\section{BIBLIOGRAFIA}

ALCOFORADO, M.J.; NUNES, M.F;; GARCIA, J.C. (1997) "Climat et société à Lisbonne". Publications de l'Association Internationale de Climatologie, vol. 10, pp. 75-83.

ALCOFORADO,M.J.;NUNES,M.F.; GARCIA, R. (a)-"A percepção das relações clima e saúde pública em Lisboa, no sec XIX, através da obra de Marino Miguel Franzini". Submetido à Revista Portuguesa de Saúde Pública. Lisboa.

ALCOFORADO, M.J.; NUNES, M.F.; GARCIA,J.C.; TABORDA, J.P. (b) - "Climate reconstruction in Portugal during the Late Maunder Minimum". Submetido à revista The Holocene.

ALCOFORADO, M.J.- "Atlas das variações climáticas na Europa". (Recensão). Finisterra, XXXIII, 66, no prelo.

BÄRRING, L. (1992) - "Climatic change or climate variation - the image we convey". Proceedings of the Pre-Congress Meeting of the Commission on Climatology, University Park, Pennsylvania, pp. 10-16.

BARRIENDOS, M. (1994) - El Clima histórico de Catalunya. Aproximación a sus características generales (ss XV-XIX). Dep. Geog. Fis., Dissertação de Doutoramento apresentada à Universidade de Barcelona.

BARRIENDOS-VALLVÉ, M. (1997) - "Climatic variations in the Iberian Peninsula during the late Maunder Minimum (AD 1675-1715): an analysis from rogation ceremonies". The Holocene, 7,1,pp. 105-110.

BARRIENDOS, M. ; GARCIA, J.; MÁRTIN-VIDE, J.; NUNES, M.F.; PEÑA, J.C.; ALCOFORADO, M.J. (1997) - "18th Century instrumental meteorological series in the Iberian Peninsula. General Characterisitics and climatic utility". Actas da Conferência "Toaldo e il suo tempo" (1719-1797). Pádua-10-14 Nov., 9p.pol.
BOTELHO, L. (1998) - "Perigos do sobreaquecimento da Terra segundo Robert Watson. Mudança climática mata mais". o Público, 25 de Janeiro.

BRADLEY, R.S.; JONES, P.D.,Ed. (1995, $2^{\text {nd }}$ ed.) - Climate since A.D. 1500 , Routledge, London.

BRAZDIL, R. et al. (1994) - "Reconstruction of the climate of Bohemia and Moravia in the period of 1615 to 1715 on the basis of written sources", in B. Frenzel; C. Pfister e B. Gläser (ed.) Climatic Trends ans anomalies in Europe 1675-1715, Fischer, Stuttgart, pp. 109-121

BRIFFA, K.R.; JONES, P.D.; SCHWEINGRUBERT, OSBORN, T.J. (1998) - "Influence of volcanic eruptions on Northern Hemisphere summer temperature over the past 600 years". Nature, 393, pp.450-455.

DAVIES, TREVOR (1998) - Annual to Decadal Variability in Climate in Europe (ADVICE), Final Report, June, Part A.

DAVEAU, S. (1997) - "Os tipos de tempo em Coimbra (Dez. 1663-Set.1665), nas Cartas do Padre António Vieira". Finisterra, Lisboa, XXXII (64), pp.109-115.

EDDY, J.A. (1976) - "The Maunder Minimum". Science, 192, pp. 1189-1202

FRENZEL, B.; C. PFISTER E B. GLÄSER (ed.) (1994) - Climatic trends and anomalies in Europe 1675-1715: Fischer, Stuttgart.

GROVE, J.M. (1988) - The Little Ice Age, Methuen, London. 498p.

GROVE, R.H. (1998) - "Global impact of the 1789-93 El Niño". Nature, 393, pp.318-319.

HARE, F. K. (1985) - "Climatic variability and climatic changes". In KATES, R.W. , AUSUBEL, J.H. e BERBERIAN, M. ed.Climat impact assessment. SCOPE 27, Wiley, Chichester, pp. 37-68.

HEGERL, G. (1998) - "The past as a guide to the future". Nature, 392, pp.758-759.

HOUGHTON, J.T. et al., ed. (1990) - Climate Change. The IPCC Scientific Assessment. WMO, UNEP. University Press. Cambridge.

HOUGHTON, J.T. et al., ed. (1996) - "Climate Change 1995. Second Assessment Report of the IPCC, WMO, UNEP". University Press. Cambridge.

HUGHES, M.K; DIAZ, H.F. (1994) - "Is there a medieval warm period, and if so, where and when?" Climatic Change, vol.26: 109-142.

JOUSSAUME, S; GUIOT, J. (1999)--"Comment réconcilier modèles numériques et données?" La Recherche, ${ }^{\circ} 311$, Junho, pp.54-59.

LAMB, H. (1982)-Climate History and the modern world. Methuen. London.

LABEYRIE, L.; JOUZEL,J. (1999) - "Les soubressauts millénaires du climat". La Recherche, n' 311, Junho, pp. 60-61 
LEAN, J. (1996) - "Reconstruction of past solar variability".In Jones, P.; Bradley, R.; Jouzel. (ed.) Climatic variations and forcing mechanisms of the last 2000 years, Springer, Berlin, pp. 519-532 .

LE ROY LADURIE, E. (1983) - Histoire du climat depuis l'an mil. T II, Flammarion, Paris.

LUTERBACHER, J. et al. (1997) - ADVICE - 18 month Progress report. University of Bern.

LUTERBACHER, J. (1998) - "Monthly sea level pressure patterns during the Late Maunder Minimum (1675-1715) compared with $20^{\text {th }}$ century circulation". Abstracts from The Second International Climate and History Conference. CRU, University of East Anglia. 7-11 September, p.3.

LUTERBACHER J., et al. (1999) - "Reconstruction of Monthly Mean Sea Level Pressure over Europe for the Late Maunder Minimum period (1675-1715) based on canorical correlation analysis". Submetido ao International Journal of Climatology.

MAHERAS, P.; GUIKA, S.;VAFIADIS, N. ALCOFORADO, M.J. (1995) - "Relations entre les périodes sèches et humides et les indices de circulation atmosphérique au Portugal durant la dernière période séculaire". Publications de l'Association Internationale de Climatologie, vol.7, Toulouse, pp. 241-248.

MANLEY, G. (1974) - "Central England temperatures: monthly means 1659 to 1973 ", Quart. J. Roy. Meteor. Soc., vol.100, pp.389-405.

MANN,E.M.;BRADLEY, R.;HUGHES, M. (1998) - "Global-scale temperature patterns and climate forcing over the past six centuries". Nature, 392, pp.779-787.

MARTÍN-VIDE, J.; BARRIENDOS-VALLVÉ, M. (1995) - "The use of rogation ceremony records in climatic reconstruction: a case study from Catalonia (Spain)", Climatic Change, 30 , pp. 201-221

MÖRNER, N.A (1994) - "The Maunder Minimum". In B. Frenzel; C. Pfister e B. Gläser (ed.) Climatic Trends ans anomalies in Europe 1675-1715, Fischer, Stuttgart, pp.1-8.

NUNES, M.F.(1997)-Asobservaçōes meteorológicas na Academia das Ciências: una leitura cientifica de Lamego (1770-1784), Comunicação apresentada no Encontro "Alcipe e as Luzes", Fundação das Casas de Fronteira e Alorna, Lisboa, Maio, 12 p.pol.

PALMA- FERREIRA. J. (1981)- Subsidios para uma bibliografia do memorialismo português. Lisboa, B.N.

PEIXOTO, J.P. (1987) - As Variações do Clima e o Ambiente. O Homem, o clima e o ambiente. II. Secretaria de Estado do Ambiente. Lisboa.

PFISTER, C. (1988) - Klimageschichte der Schweiz von 1525-1860 und seine Bedeutung in der Geschichte von Bewölkerung und Landwirtschaft. Haupt, Bern und Stuttgart, 184p.
PFISTER, C. (1992) - "Five Centuries of Little Ice Age climate in western Europe". In Mikami, T. (ed.) Proceedings of the International Symposium on the Little Ice Age Climate. Tokyo. Tokyo Metropolitan University, pp. 208-214.

PFISTER, C. (1994) - "Spatial patterns of Climatic change in Europe". In Frenzel et al ed. - Climatic trends and anomalies in Europe 1675-1715. Fischer, Stuttgart, pp. 287-317.

PFISTER, C.; BAREISS, W. (1994) -- "The climate in Paris between 1675 and 1715 according to the Meteorological Journal of Louis Morin". In Frenzel et al ed. - Climatic trends and anomalies in Europe 1675-1715. Fischer, Stuttgart, pp. 151$-171$

PFISTER, C. (1995) - "Monthly temperature and precipitation in Central Europe from 1525-1979: quantifying documentary evidence on weather and its effects". In Bradley, R.S.; Jones, P. (eds.) Climate since A.D. 1500, London, Routledge, pp.118-142

PFISTER, C. et al. (1994) - "The creation of high resolution spatiotemporal reconstructions of past climate from direct meteorological observations and proxy data. Methodological considerations and results". In Frenzel, B.; C. Pfister e B. Gläser (ed.) - Climatic trends and anomalies in Europe 1675-1715. Fischer, Stuttgart, pp. 329-376.

PFISTER, C. (1999) - "Le puzzle climatique des historiens". La Recherche, $\mathrm{n}^{\circ} 311$, Junho, pp. 64-68.

PYLE, D.M. (1998) - "How did the summer go?" Nature, 393, pp.415-147.

SCHÖNWIESE, C.-D.; RAPP, J. (1997) - Climate trend atlas of Europe based on observations 1891-1990. Kluwer Academic Publishers. Dordecht.

SILVA,J.S. da (1931)-Memórias de José Soares da Silva, Académico do Número da Academia Real de História Portuguesa. 1701-1708. Edição da Misclânea de Oeiras, 136 p.

WANNER, H. (1994) - "Synoptic interpretation of monthly weather maps for the late Maunder Minimum (1675-1704)". In Frenzel, B.; C. Pfister e B. Gläser (ed.) - Climatic trends and anomalies in Europe 1675-1715. Fischer, Stuttgart, pp. 401-424

WANNER, H. et al, (1995) - "Wintertime european circulation patterns during the Late Maunder Minimum Cooling Period". Theor.Appl.Climatology, 5, pp. 167-175.

WANNER, H. et al. (1997) - "Global Climate change and variability and its influence on alpine climate - Concepts and observations". Theor.Appl.Climatology, 58, pp.221-243,

WANNER, H. (1998) - "How far do we understand decadal to century scale climate variability and change in the European Alps?" In Climate and Environmental Changes, Abstracts of the Pre-Regional Conference of the Commission on Climatology (UGI), Lisboa, pp. 51-52. 